\title{
ANKSTYVA AKTYVI REABILITACIJA PO IZOLIUOTU LENKIAMŲJŲ PLAŠTAKOS SAUSGYSLIŲ SUŽALOJIMO
}

\author{
Karolina Venslauskaitė ${ }^{1}$, Karolina Jurelevičiūtè ${ }^{2}$, Karolis Varkalys ${ }^{2}$, Kęstutis Braziulis ${ }^{2}$ \\ ${ }^{l}$ Lietuvos sveikatos mokslu universiteto ligoninè, Plastinès ir rekonstrukcinès chirurgijos klinika, \\ ${ }^{2}$ Lietuvos sveikatos moksly universiteto Medicinos fakultetas
}

Raktažodžiai: plaštakos traumos, antroji zona, lenkiamosios sausgyslès, lenkiamųjų sausgyslių sužalojimai, ankstyva aktyvi reabilitacija.

\begin{abstract}
Santrauka
Darbo uždavinys. Išmatuoti pirštų lenkimo amplitudès pokyčius goniometru, taikant ankstyvą aktyvią reabilitaciją.

Tyrimo metodika. Atliktas prospektyvinis tyrimas, $\underset{i}{i}$ kuri įtraukti 18 Lietuvos sveikatos mokslų universiteto ligoninès Kauno klinikų pacientų su izoliuotomis plaštakos lenkiamujų sausgyslių traumomis, gydytų nuo 2017 metų rugsèjo iki 2018 metų gegužès mènesio. Pacientams, iš kurių 13 vyrų (72,2 proc.), 5 moterys ( 27,8 proc.), buvo taikyta ankstyva aktyvi reabilitacija. Tiriamujų amžiaus mediana 48,5 (20 -68) metų. Gauti rezultatai lyginti neparametriniu Vilkoksono (Wilcoxon) kriterijumi, statistiškai reikšmingu skirtumu laikème $p<0,05$. Apžvelgę tarptautinès literatūros rekomendacijas, sudarème operacini protokolą, kuriuo rèmėmès tyrimo metu.

Rezultatai. İvertinus pirštų judesių amplitudę goniometru po 2 ir po 4 savaičiu gauti rezultatai atitinkamai: mediana $85(65$ - 90) laipsniai ir mediana 110 $(85-120)$ laipsnių. Gautas statistiškai reikšmingas skirtumas $\mathrm{p}<0,001$.

Išvada. Ankstyva aktyvi „Saint John“ reabilitacija yra naujas ir efektyvus metodas pacientams po izoliuotų plaštakų lenkiamujų sausgyslių sužalojimų, jeigu užtikrinaname tinkamą sausgyslès susiuvimą ir pooperacinę priežiūrą.
\end{abstract}

\section{Ivadas}

İvairaus pobūdžio plaštakų sužalojimai reikšmingai didina žmonių nedarbingumą bei neigalumą. Daugumą tokių plaštakos sužalojimų sudaro sausgyslių pažeidimai. Norint išvengti dažnų pooperacinių komplikacijų, pakartotinio sausgyslès plyšimo ar prirandejimo prie aplinkinių audinių bei sąnarinių kontraktūrų, labai svarbu pasirinkti tinkamą gydymą ir reabilitaciją. Mes atkreipème demesị i lenkiamujų sausgyslių pažeidimus II plaštakos zonoje, kuri pasaulyje dar apibūdinama kaip ,, no man's land“. Šis terminas pirmą kartą paminètas 1918 metais Bunnell [1]. Jis taip apibūdino zoną, kurioje lenkiamosios sausgyslès pereina per apvalkalą ir sausgyslinius žiedus bei patarè, kad chirurgai būtų atsargūs siūdami sausgysles šioje zonoje dèl dažno jų prirandèjimo prie aplinkinių audinių.

Per paskutinius du dešimtmečius lenkiamujų sausgyslių rekonstrukcijos ir reabilitacijos metodai ženkliai pasikeitè. Šiuo metu atkreipiamas dèmesys ị tvirtą ir patikimą daugiasiję sausgyslès siūlę, pagrindinių sausgyslinių žiedų išsaugojimą bei ankstyvą aktyvią reabilitaciją, siekiant atstatyti kuo geresnę pažeistos plaštakos funkciją [2]. Tvirtas sausgyslès susiuvimas bei sausgyslinių žiedų išsaugojimas leidžia anksti pradèti aktyvią reabilitaciją su mažesne pooperacinio plyšimo rizika [3]. Nepriklausomai nuo operacinio metodo pasirinkimo, galimas susiūtos sausgyslès prirandèjimas prie aplinkinių audinių ar sąnario kontraktūra, ir tai turi ịtakos galutiniam sausgyslès, kartu ir visos plaštakos, funkcijos atsistatymui. Siekiant geriausios pooperacinès plaštakos funkcijos atstatymo rezultatų - reabilitacija yra būtina [4].

Lenkiamujų sausgyslių sužalojimai dažnai ịvyksta buitinejje aplinkoje susižeidžiant peiliu, stiklo ar veidrodžio šukemis, taip pat dirbant su grandininiu pjūklu, žoliapjove ar kitais darbo įrankiais. Pagal tarptautinę rankos chirurgijos draugijų federecijos topografinę plaštakos klasifikaciją (angl. International Federation of Societies for Surgery of the Hand) išskiriamos I-V plaštakos zonos.

LSMUL Kauno klinikose, Plastinès ir rekonstrukcinès chirurgijos klinikoje, 2014m. - 2016m. gydèsi net 1207 pacientai, patyrę plaštakos traumas. Nustatyta, jog dažniausiai lenkiamujjų sausgyslių sužalojama sritis - II-oji plaštakos zona [6]. Pietų Korèjoje, Seulo ligoninëje atliktame 9 metus trukusiame tyrime buvo analizuoti 533 pacientai su traumi- 
niais rankų sausgyslių sužalojimais. Lenkiamujų sausgyslių pažeidimai II-oje plaštakos zonoje sudare didžiausią sausgyslių sužalojimų dali ( 52,4 proc.) [7].

Darbo tikslas: ivvertinti ir aptarti rezultatus, gautus pritaikant ankstyvą aktyvią reabilitaciją po lenkiamujų plaštakos II-osios zonos sausgyslių sužalojimų.

\section{Tyrimo objektas ir metodika}

Šiame straipsnyje aptarsime gautus rezultatus pritaikant ankstyvą aktyvią reabilitaciją pagal vieną naujausių ir pasaulyje šiuo metu rekomenduojamą naudoti „The Saint John“ protokolą [8]. İ tyrimą buvo ịtraukti visi pacientai nuo 18 iki 70 metų amžiaus, patyrę izoliuotus plaštakos giliujų lenkiamųų sausgyslių sužalojimus antroje plaštakos zonoje 24 valandų laikotarpiu. Neįtraukti pacientai, plaštakos traumą patyrę jau ne pirmą kartą, turintys plaštakos sąnarių degeneracinių pakitimų ar jungiamojo audinio ligų, bei tie, kuriems buvo nustatyta žaizdos infekcija.

Taikant ankstyvą aktyvią reabilitaciją, labai svarbu sausgyslès siūlès tvirtumas. Apžvelgę tarptautinès literatūros rekomendacijas, sudarème operacini protokolą, kuriuo rèmèmès tyrimo metu. Egzistuoja daugybė skirtingų lenkiamųu sausgyslių operacinès technikos būdų. Renkantis atsižvelgiama ị sausgyslès siūlès sijų skaičių, periferinị apsiuvimą, ịvertinamas mazgo sustorejimas, galintis turèti įtakos sausgyslès paslankumui [2, 3]. Daugumoje literatūros šaltinių rekomenduojama, jog sausgyslių siūlèse būtų naudojamos

PRATIMAI, GERINANTYS RANKOS FUNKCIJA, PO LENKIAMŲJŲ SAUSGYSLIŲ OPERACIJOS

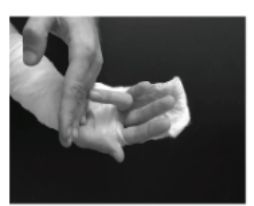

1. Su nepažeista ranka sulenkti pažeistą/us pirštus j̇ delną. Sulenkus pirštus atpalaiduoti, leisti išsitiesti patiems. Pratimą pakartoti 10 kartų.

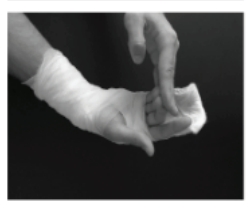

2. Sveikos rankos plaštaką padèti ties pažeistos rankos delno pagrindu ir aktyviais pirštu judesiais stengtis paliesti sveikają plaštaką. Pratimą pakartoti 10 kartų.

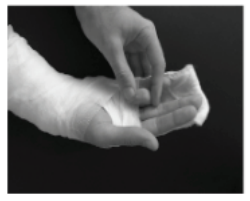

3. Su sveika ranka šiek tiek sulenkti pirštus per krumplius bei aktyviais judesiais lankstyti pirštus per artimiausius pirštų sąnarius. Pratimą pakartoti 10 karty.

Visus 3 pratimus atlikti po 10 kartų kas valandą.

1 pav. Ankstyvios aktyvios „Saint John“ reabilitacijos protokolas. Mankštai reikalingi pratimai, su kuriais buvo supažindinti visi tyrime dalyvavę pacientai ne mažiau kaip 4 gijos $[9,10]$. Savo protokole pasirinkome 6 gijų, užrakinamą trigubą „Kessler“ siūlę, naudojant pintą, netirpų 2-3/0 siūlą bei uždedant papildomą apsukinę 5/0 netirpaus monofilamentinio siūlo siūlę. Visi pacientai buvo operuoti laidinëje nejautroje vietinès išemijos sąlygomis su varžčiu ant žasto apatinio trečdalio, operacinị lauką paruošiant antiseptiniu 70 proc. 2-propanolio ir 0,1 proc. 1,3-butadinolio tirpalu, žaizdos kraštus pratęsiant, atliekant „Z“ formos pjūvị. Operacijos metu buvo išsaugoti sausgysliniai žiedai, o siūlès atstumas nuo sausgyslès galų - 7-10 mm. Oda susiūta 4/0 netirpiu monofilamentiniu siūlu pavienèmis siūlèmis.

Iš karto po operacijos buvo taikyta imobilizacija dorsalinio bloko ịtvaru. Reabilitacija pradedama 3-4-tą pooperacinę parą. Pacientai supažindinami su reabilitacijos protokolu, parodomi bei paaiškinami mankštai reikalingi pratimai, kurie atliekami iki 10 kartu per valandą (1 pav.). Iki antros pooperacinės savaitės atliekama pasyvi pirštų fleksija apšilimui, vèliau aktyvi fleksija iki pusès kumščio. Mankštų metu buvo rekomenduojama nevartoti nuskausminamųjų vaistų, kad pacientai adekvačiai reaguotų ị skausmą bei nenaudotų didelès jẻgos judinant pirštus. Nuo antros savaitės pradedama aktyvi sinergistinių pratimų programa - fleksija nuo pusės iki pilno kumščio. Pratimų pagalba iki šeštos pooperacinès savaitès stengiamasi pasiekti pilną kumščio fleksiją. Plaštakų pirštu judesiu amplitudę matuodami goniometru vertinome po 2 ir 4 savaičių. Pasibaigus reabilitacijos programai nuimamas itvaras, pacientas gali pradeti naudotis ranka atliekant nesunkius darbus, kelti daiktus iki 5 kilogramų. Pirštų ar plaštakos tiesiamasis delninis ịtvaras naudojamas naktị esant tarpfalanginio sąnario fleksijos kontraktūroms.

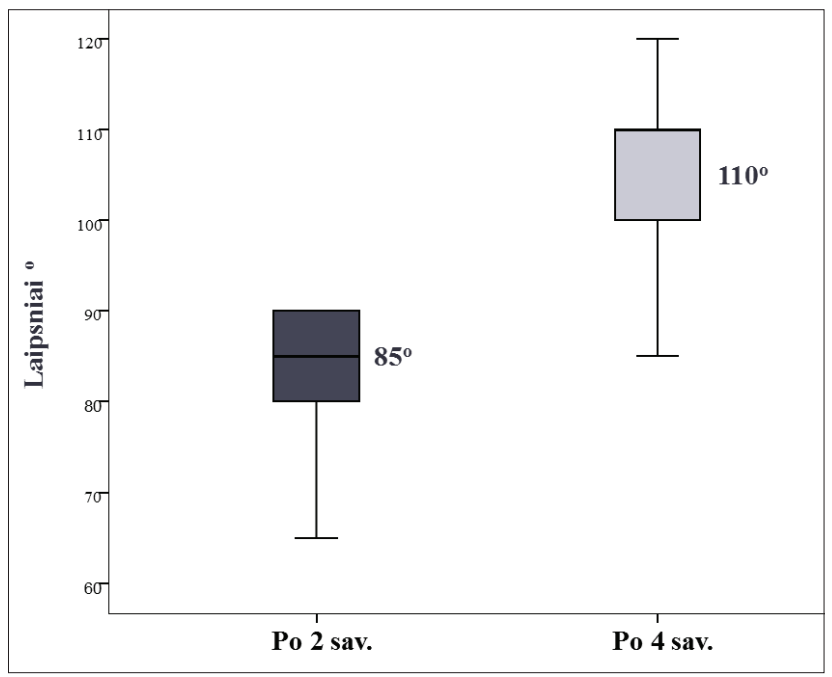

2 pav. Judesių amplitudès rezultatai pacientams po ankstyvos aktyvios reabilitacijos po 2 ir po 4 sav. Rezultatai pateikti medianomis. Skirtumas statistiškai reikšmingas $\mathrm{p}<0,001$. 
Statistinė duomenų analizė atlikta naudojant IBM SPSS Statistics 23.0 paketą. Skaičiavimams buvo taikomi neparametriniai statistiniai metodai - chi kvadratas, Vilkoksono kriterijus. Rezultatai pateikiami medianomis, skliausteliuose nurodomos minimalios bei maksimalios reikšmès (min-max). Skirtumas laikytas statistiškai reikšmingu, jei $\mathrm{p}<0,05$.

\section{Diskusija}

Lenkiamujų sausgyslių sužalojimai dažnai ịvyksta buityje susižeidžiant peiliu, stiklo ar veidrodžio šukèmis, taip pat dirbant su grandininiu pjūklu, žoliapjove ar kitais darbo įrankiais. Pagal tarptautinę rankos chirurgijos draugijų federecijos topografinę plaštakos klasifikaciją (angl. International Federation of Societies for Surgery of the Hand) išskiriamos I-V plaštakos zonos. Ši klasifikacija leidžia nustatyti proksimalinio sausgyslès galo retrakciją [1].

LSMUL Kauno klinikose, Plastinès ir rekonstrukcinès chirurgijos klinikoje, $2016 \mathrm{~m}$. gydèsi net 115 pacientu patyrusių plaštakos traumą. Nustatyta, jog dažniausiai lenkiamujų sausgyslių sužalojama sritis - II-oji plaštakos zona. Pietų Korejoje, Seulo ligoninejje atliktame 9 metus trukusiame tyrime buvo analizuoti 533 pacientai su trauminiais ranku sausgyslių sužalojimais. Lenkiamujų sausgyslių pažeidimai II-ojoje plaštakos zonoje sudare didžiausią sausgyslių sužalojimų dalị $(52,4$ proc.) [2].

Tvirta ir patikima sausgyslès siūlè, pagrindinių sausgyslinių žiedų išsaugojimas bei ankstyva aktyvi reabilitacija taikyta pacientams, siekiant atstatyti kuo geresnę pažeistos plaštakos funkciją bei norint išvengti dažnų pooperacinių komplikacijų: pakartotinio sausgyslès plyšimo, prirandèjimo prie aplinkinių audinių ar sąnarinių kontraktūrų. Siekiant geresnių ir patikimų tyrimo rezultatų, sudarinejjant operacini bei reabilitacinį protokolus, apžvelgème naujausios tarptautinès mokslinès literatūros rekomendacijas. Ankstyva aktyvi „Saint John“ reabilitacija po lenkiamujų plaštakų sausgyslių sužalojimo šiuo metu sèkmingai ir plačiai taikoma daugelyje šalių. [7] Labai svarbu, kad pacientas būtų orientuotas ir suinteresuotas kasdien atlikinèti mankštai reikalingus pratimus, būtina aiškiai parodyti ir išmokyti, kaip teisingai juos atlikti. (1 pav.) Šis reabilitacijos protokolas netinkamas pacientams, kuriems taikoma imobilizacija po mišrių plaštakos sužalojimų, esant kaulų ar neurovaskulinių pluoštų pažeidimams. Sausgyslių siuvimui pasirinkta 6 gijų, užrakinama triguba „Kessler“ siūlè pakankamai tvirtai išlaikẻ aktyvios reabilitacijos metu visiems tyrime dalyvavusiems pacientams.

\section{Rezultatai}

Nuo 2017 metų rugsèjo mènesio iki 2018 metų gegužès mėnesio ištyrėme 18 Lietuvos sveikatos mokslų universiteto ligoninès Kauno klinikų pacientų, kuriems buvo taikytas operacinis gydymas Plastinės ir rekonstrukcinès chirurgijos skyriuje po izoliuotų giliųų lenkiamujų sausgyslių pažeidimų II-ojoje plaštakos zonoje. Tarp pacientų buvo 13 vyrų ( 72,2 proc.) ir 5 moterys (27,8 proc.). Amžiaus mediana buvo 48,5 metai. Ivertinus pirštų judesių amplitudę goniometru po 2 ir po 4 savaičiu gauti rezultatai atitinkamai: mediana $85(65$ - 90) laipsniai ir mediana 110 (85 - 120) laipsnių (2 pav.). Šie rezultatai lyginti neparametriniu Vilkoksono (Wilcoxon) kriterijumi ir gautas statistiškai reikšmingas skirtumas $\mathrm{p}<0,001$.

\section{Išvada}

Ankstyva aktyvi „Saint John“ reabilitacija yra naujas ir efektyvus metodas pacientams po izoliuotų plaštakų lenkiamujjų sausgyslių sužalojimų, jeigu užtikrinaname tinkamą sausgyslès susiuvimą ir pooperacinę priežiūrą.

\section{Literatūra}

1. Hage JJ (2017) History Off-Hand : Bunnell ' s No-Man ' s Land. https://doi.org/10.1177/15589447177443337

2. Tang JB (2018) Recent evolutions in flexor tendon repairs and rehabilitation.

3. Lutsky KF, Giang EL, Matzon JL. Flexor tendon injury, repair and rehabilitation. Orthop Clin North Am 2015; 46:67-76 . https://doi.org/10.1016/j.ocl.2014.09.004

4. Sanmartín-Fernández M, Fernández-Bran B, Couceiro-Otero J. Home-based rehabilitation in the postoperative treatment of flexor tendon repair. Rev Esp Cir Ortop Traumatol 2017; 61:224-232.

https://doi.org/10.1016/j.recote.2017.06.004

5. Lineberry KD, Shue S, Chepla KJ The management of partial zone II intrasynovial flexor tendon lacerations. Plast Reconstr Surg 12018.

6. Lapegue F, Andre A, Brun C. et al. Traumatic flexor tendon injuries. Diagn Interv Imaging 2015; 96:1279-1292 .

https://doi.org/10.1016/j.diii.2015.09.010

7. Kim JS, Sung SJ, Kim YJ, Choi YW. Analysis of pediatric tendon injuries in the hand in comparison with adults. Arch Plast Surg 2017; 44:144-149. https://doi.org/10.5999/aps.2017.44.2.144

8. Higgins A, Lalonde DH. Flexor tendon repair postoperative rehabilitation: The Saint John Protocol. Plast Reconstr surgery Glob open 2016; 4:e1134.

https://doi.org/10.1097/GOX.0000000000001134

9. Giesen T, Calcagni M, Elliot D. Primary flexor tendon repair with early active motion: experience in Europe. Hand Clin 2017; 33:465-472 . https://doi.org/10.1016/j.hcl.2017.03.001

10. Tang JB, Zhou X, Pan ZJ. et al. Strong digital flexor tendon repair, extension-flexion test, and early active flexion: experience in 300 tendons. Hand Clin 2017; 33:455-463.

https://doi.org/10.1016/j.hcl.2017.04.012 


\section{4}

EARLY ACTIVE REHABILITATION AFTER FLEXOR TENDON INJURIES OF THE HAND

\section{K.Venslauskaitė, K.Jurelevičiūtė, K.Varkalys, K.Braziulis}

Key words: hand traumas, zone two, flexor tendon, flexor tendon injuries, early active rehabilitation.

Summary

Aim. To analyze results, after using early active rehabilitation in flexor tendon injuries in zone II of the hand.

Methods. We conducted a prospective cohort study of 18 patients in LUHS KC Plastic and reconstructive surgery department with isolated flexor tendon injuries of the hand. All patients were treated from September 2017 to May 2018. There were 13 men (72,2 perc.), 5 women (27,8 perc.) with age median 48,5 (2068 ) years. Results were compared using Wilcoxon criteria, P values of less than 0.001 were considered significant. We reviewed international recommendations and created an operation protocol on which we relied on.
Results. A goniometer was used to measure angles of the injured fingers. After surgery all patients had rehabilitation and have been followed up after 2 weeks and after 1 month. The results accordingly were: median $85(65-90)$ degrees and $110(85-120)$ degrees. There was a significant difference $\mathrm{P}<0.001$.

Conclusion. Early active rehabilitation is a new and effective method for the patients after isolated flexor tendon injuries if used under proper tendon suturing and post-operative care circumstances.

Correspondence to: venslauskaite@gmail.com

Gauta 2018-06-03 